\title{
The Role of Membrane Lipids in the Regulation of Immune Cell Activity
}

\author{
Fredrick G. Karnell John G. Monroe \\ Department of Pathology and Laboratory Medicine, University of Pennsylvania, Philadelphia, PA, USA
}

\section{Key Words}

B cells $\cdot$ T cells $\cdot$ Lipid rafts $\cdot$ Signaling $\cdot$ Statins

\section{Summary}

Engagement of immune receptors by antigen triggers processes that culminate in activation, cell proliferation, differentiation and effector functions. A growing body of evidence suggests that it is within specialized membrane regions called lipid rafts that the initiation and propagation of the signaling events taking place in immune cells occurs. These specialized membrane compartments are enriched in cholesterol and glycolipids and contain many lipid-modified signaling proteins such as GPI (glycosylphosphatidylinositol)-linked proteins, Src family tyrosine kinases and other adaptor proteins. By confining certain signaling molecules in membrane subdomains, lipid rafts have been proposed to function as platforms for the formation of multi-unit transduction complexes. Therefore, it has been suggested that the translocation of immune receptors into lipid rafts regulates immune cell activation. In lymphocytes it has been shown that immune receptors become lipid raft-associated upon antigen cross-linking, and signaling complexes are formed when additional components of the signaling pathways are recruited to lipid rafts. Furthermore, substantial evidence from a number of experiments shows that the integrity of lipid rafts is crucial for the initiation and maintenance of intracellular signals. Recent studies have also shown that the access and translocation of immune receptors to lipid rafts are developmentally regulated (immature versus mature cells, naïve versus effector) and that the cholesterol content plays an important role in maintaining plasma membrane heterogeneity and influencing a variety of cellular processes including signaling, adhesion, and permeability. The aim of this review is to examine the role membrane lipids play in regulating immune activation.

\section{Schlüsselwörter \\ B-Zellen · T-Zellen · Lipid-Rafts · Signalprozesse · Statine}

\section{Zusammenfassung}

Die Bindung von Immunrezeptoren durch Antigen triggert Prozesse, die zu Zellaktivierung, Zellproliferation, Zelldifferenzierung und Realisierung zellulärer Effektorfunktionen führen. Es ist zunehmend belegt, dass die Initiierung und Ausbreitung der Signalprozesse in Immunzellen an spezialisierte Zellmembrandomänen, so genannte Lipid-Rafts, gebunden ist. Lipid-Rafts enthalten Cholesterol und Glykolipide sowie eine Vielzahl durch Lipide modifizierter Signalproteine wie GPI (Glycosylphosphatidylinositol)-verankerte Proteine, die Tyrosin-Kinasen der Src-Familie und andere Adapterproteine. Die Konzentrierung definierter Signaltransduktionsmoleküle auf Subdomänen der Zellmembran legt die Möglichkeit nahe, dass Lipid-Rafts als kleinste Einheit die Basis von Multi-Unit-Signaltransduktionskomplexen bilden und die Translokation von Immunrezeptoren in die Lipid-Rafts die Aktivität von Immunzellen reguliert. Es ist gezeigt worden, dass auf Lymphozyten exprimierte Immunrezeptoren mit Lipid-Rafts assoziieren, wenn es zur Quervernetzung der Rezeptoren durch Antigen kommt, und dass Signaltransduktionskomplexe gebildet werden, wenn weitere Elemente der Signaltransduktionskaskade in die LipidRafts einbezogen werden. Experimentelle Untersuchungen belegen, dass die Integrität der Lipid-Rafts von wesentlicher Bedeutung für die Initiierung und Aufrechterhaltung intrazellulärer Signale ist. Neue Untersuchungsergebnisse weisen zudem darauf hin, dass die Integration der Immunrezeptoren in die Lipid-Rafts durch das Entwicklungsstadium der Zelle reguliert wird (unreife Zelle versus reife Zelle, immunologisch naive Zelle versus Effektorzelle), und dass der Gehalt an Cholesterol eine zentrale Rolle für die Aufrechterhaltung der Heterogenität der Plasmamembran und die Regulierung zellulärer Prozesse wie Signaltransduktion, Adhäsion und Permeabilität spielt. Die vorliegende Übersichtsarbeit fasst die Rolle der Zellmembranlipide für die Regulation der Aktivität von Immunzellen zusammen.

\begin{tabular}{ll}
\hline KARGER & @ 2006 S. Karger GmbH, Freiburg \\
Fax +4976145207 14 & Accessible online at: \\
$\begin{array}{l}\text { E-mail Information@Karger.de } \\
\text { www.karger.com }\end{array}$ & www.karger.com/tmh
\end{tabular}

Dr. John G. Monroe

Department of Pathology and Laboratory Medicine

University of Pennsylvania, 421 Curie Boulevard

BRB2/3, Room 311, Philadelphia, PA 19104, USA

Tel. +1 215-8982873, Fax -5732014

E-mail monroej@mail.med.upenn.edu 


\section{Introduction}

Biological membranes are formed by a bilayer of lipids, with a hydrophobic core formed by the hydrocarbon chains of lipids. In the original fluid mosaic model of biological membranes, lipids form a homogeneous two-dimensional solvent phase for membrane proteins [1]. Yet, membrane lipids comprise several hundreds of distinct molecules that exist in different physical states controlled by several physicochemical parameters such as the temperature, presence of cholesterol and chemical nature of the hydrocarbon chains [2]. Thus, biological membranes are probably better described as a 'mosaic of lipid domains' rather than a homogeneous fluid mosaic. Membrane cholesterol, for instance, is unevenly distributed into cholesterol-rich and cholesterol-poor domains, consistent with the notion that specialized lipid domains with specific biochemical composition and physicochemical properties do exist in membranes $[2,3]$. Among these domains, those containing sphingolipids and cholesterol, referred to as lipid rafts or caveolae (when associated with the integral membrane protein caveolin), have been extensively studied [4, 5]. Membrane lipids are amphiphilic molecules, indicating that they are formed of 2 parts, one hydrophobic and the other hydrophilic. The hydrophilic part interacts with water, whereas the hydrophobic part has to find a hydrophobic phase to avoid contact with water [2]. Therefore, membrane lipids self-organize into supra-molecular complexes in which only their hydrophilic part interacts with water.

Recent work has given rise to a fundamentally new way of thinking about biological membranes. Contrary to earlier views, we now know that lipids do not partition homogeneously in membranes, but can be organized into domains in the bilayer. These domains can be isolated from most mammalian cells, but different experimental approaches have led to a lack of standardized nomenclature. These domains can be referred to as TIFF (Triton-insoluble floating fraction), GEMs (glycolipid-enriched membranes), or DIGs (detergent-insoluble glycolipid-enriched membranes), but hereafter will be as lipid rafts [6-9]. As suggested, lipid rafts are specialized membrane domains enriched in certain lipids cholesterol and proteins. Many recent studies have focused on these higher ordered sphingolipid/cholesterol enriched membrane microdomains. It has been suggested that lipid raft domains play important roles in signaling, because several receptors, including the B cell receptor (BCR) [10], T cell receptor (TCR) [11], FceR [12] and insulin receptor [13] are observed to redistribute from the detergent-soluble, lipid-disordered to the GM1enriched, detergent-insoluble compartment upon ligand binding. It is for these reasons that lipid rafts are believed to serve as signaling platforms during immune cell activation.

This review will focus on the recent advances in the immune receptor-signaling field with a particular emphasis on the role of lipid microdomains in immune activation. The role of lipid rafts in BCR, TCR and FcR signaling will be discussed. Lipid rafts have also been implicated in host-pathogen interactions and represent possible entry and assembly sites for a number of pathogens. Finally, the relevance of lipid rafts as potential therapeutic targets will be discussed.

\section{Lipid Rafts and the Regulation of Immunoreceptor Signaling}

B Cells

All B lymphocytes can be characterized by the expression of membrane-bound immunoglobulin molecules that recognize foreign pathogens, such as bacteria, viruses, parasites and other antigens. This membrane-bound immunoglobulin or BCR has 2 key functions: the generation of intracellular signals resulting in gene transcription and $\mathrm{B}$ cell activation, and the presentation of antigen-derived peptides to helper T lymphocytes. The BCR is comprised of a membrane-associated immunoglobulin that lacks inherent signaling function coupled to the $\operatorname{Ig} \alpha / \operatorname{Ig} \beta$ heterodimer. The BCR's ability to signal can be attributed to the fact that each chain of this $\operatorname{Ig} \alpha / \operatorname{Ig} \beta$ heterodimer contains 2 immunoreceptor tyrosine-based activation motifs (ITAMs). These ITAMs contain tyrosine residues that, upon BCR cross-linking by antigen, are phosphorylated by the Src kinase Lyn and then serve as docking sites for the cytoplasmic kinase Syk $[14,15]$. Upon recruitment and phosphorylation of Syk, signaling pathways are activated leading to gene transcription [16].

\section{Lipid Rafts and the Initiation and Propagation of BCR Signaling}

Our group and others have shown that the BCR rapidly translocates into lipid rafts following cross-linking by antigen or anti-Ig antibodies $[10,17]$. This translocation occurs within seconds after cross-linking and is independent of tyrosine phosphorylation by Src kinases [18]. Multiple tyrosine-phosphorylated proteins are found in lipid rafts together with the BCR, such as BLNK, SHIP, Btk, Syk, Vav, PLC $\gamma-2$ and PI3K [18-20]. Upon cross-linking of the receptor, approximately $30 \%$ of the BCR pool translocates into lipid rafts. It is then endocytosed and cannot be detected on the cell surface after 30 min [18]. Pierce and colleagues [21] have shown that the ganglioside GM1, which resides almost exclusively in lipid rafts, is internalized with the BCR following cross-linking suggesting the lipid raft is internalized, not just the BCR. This internalization of the BCR then causes the down-regulation of BCR signaling and allows delivery of the antigen to the MHC class II peptide-loading compartment where it is assembled in peptide-class II complexes [21].

\section{Lipid Rafts and the Negative Regulation of BCR Signaling} Ravetch and colleagues $[22,23]$ have shown that BCR signaling can be negatively regulated by the low affinity receptor 
Fc $\gamma$ RIIB. Fc $\gamma$ RIIB contains an immunoreceptor tyrosinebased inhibitory motif (ITIM) in its cytoplasmic tail that is phosphorylated by Lyn. The SH2-containing 5'-inositol phosphatase (SHIP) is then recruited to the receptor complex where it blocks signaling by dephosphorylating phosphatidylinositol triphosphates [24]. Aman and colleagues [25] demonstrated that a fraction of FcyRIIB is constitutively present in lipid rafts. They go on to show that upon BCR and FcR ligation, the amount of Fc $\gamma$ RIIB present in lipid rafts increased, as does its phosphorylation state. The phosphatase SHIP is actively recruited into lipid rafts following negative stimulation conditions. These experiments suggest that Fc $\gamma$ RIIB negatively regulates BCR signaling inside lipid rafts. Collectively, these data suggest that lipid rafts play an important role in the initiation and regulation of BCR signaling and antigen processing. BCR signaling has also been shown to be regulated by coreceptors that control the residency of the BCR in lipid rafts.

\section{Lipid Rafts and Co-Stimulation in B Cells}

An important co-receptor for B lymphocytes is CD40. CD40, a member of the tumor necrosis factor (TNF) receptor family, modulates BCR signaling in immature and mature B cells [26]. Conflicting results exist regarding the ability of CD40 to translocate into lipid rafts. Some groups have shown that CD40 is rapidly recruited to lipid rafts following CD40 engagement $[27,28]$. Manie and colleagues [27] have shown in human monocyte-derived dendritic cells, and Bishop and colleagues [28] in mouse B cell lines that CD40 can associate in membrane lipid rafts. This association with lipid rafts allows the recruitment of TNF receptor-associated factors (TRAFs) to the CD40 cytoplasmic tail and the activation of the Lyn, a Src-kinase that constitutively resides in lipid rafts. Conversely, Pierce and colleagues [29] have observed that CD40 does not translocate into lipid rafts following engagement. Instead, cross-linking of CD40 enhances and accelerates the association of the BCR with lipid rafts, in turn reducing the amount of BCR that is internalized and degraded in mature B cells. These results suggest that CD40 can function outside lipid rafts to influence lipid raft-dependent signals in mature B cells [29].

Co-stimulation is also important for BCR signaling. The CD19/CD21 complex enhances signaling to complementtagged antigens and also reduces the threshold for B cell activation to $\mathrm{T}$ cell-dependent antigens [30]. The CD19/CD21 complex, as well as the BCR, are excluded from lipid rafts in resting B cells. However, co-ligation with the BCR or crosslinking of the CD19/CD21 complex by itself causes the translocation of the complex into lipid rafts. The co-ligation of the BCR and the CD19/CD21 complex also increases the amount of BCR that translocates into lipid rafts and prolongs the residency of the $\mathrm{BCR}$ in the lipid rafts by blocking its internalization [31, 32]. Co-ligation of the CD19/CD21 complex can, therefore, regulate the access of the BCR to the signaling enzymes found in lipid rafts and represents a way of regulating $\mathrm{B}$ cell activation.

\section{Membrane-Associated Cholesterol and BCR Signaling}

It has been shown that the presence of BCR in lipid rafts is dependant on cholesterol, since cholesterol sequestering agents inhibit the early tyrosine phosphorylation events as well as BCR-induced calcium influx [19]. Furthermore, recent evidence suggests that membrane cholesterol content may play a role in B cell development. B lymphocyte responses to similar stimuli differ dramatically at discrete stages of maturation and in different microenvironments. Mature B cells proliferate in response to BCR aggregation, as previously discussed, while bone marrow and peripheral immature B cells are not activated by signals generated through the BCR, but undergo apoptosis (deletion) or receptor modification (editing) [33]. Transitional immature B cells are a population of peripheral immature $\mathrm{B}$ cells that have recently left the bone marrow and are a critical precursor to immunocompetent mature B cells [17, 34, 35]. Our laboratory has shown that upon BCR cross-linking, transitional immature B cells undergo apoptosis, while mature B cells enter and progress through cell cycle, up-regulate proteins necessary to activate $\mathrm{T}$ cells, and manifest other processes associated with activation [33, $36,37]$. Importantly, the ligand-induced redistribution of the BCR is developmentally regulated, such that while it preferentially associates with the lipid rafts in mature cells after BCR aggregation, this inducible redistribution does not occur in transitional immature B cells [10,17]. Recently, our laboratory has explored the relationship between these responses and plasma membrane composition, namely membrane-associated cholesterol content. We have shown that membrane-associated cholesterol levels are lower in transitional immature B cells as compared to mature B cells [38]. When cholesterol is added to the membrane of transitional immature B cells (to a level seen in mature B cells), these cells phenotypically behave as mature B cells, in terms of BCR/lipid raft association and some signaling aspects [38]. These results suggest that membrane cholesterol content plays a determining role in the fate decisions of mature and transitional immature B cells to antigen.

\section{T Cells}

During development, T lymphocyte precursors migrate from the bone marrow to the thymus, where they assemble their receptors and mature into cells expressing either CD8 or CD4 on their surface [39]. These CD8 or CD4 expressing T cell subsets can then recognize small protein fragments presented on cell surface molecules encoded by MHC class I and II genes, respectively. The TCR expressed on mature T cells is responsible for antigen/MHC recognition. It is associated with the CD3 complex $(\gamma, \delta$, and $\varepsilon)$ and the disulfide-linked $\zeta-\zeta$ homodimer. Each of the CD3 chains possesses one ITAM while the $\zeta$ chain has three ITAMs. Following antigen recognition, the earliest event is the activation of the Src family kinases 
Lck and Fyn. These kinases phosphorylate the ITAMs present on the CD3- $\zeta$ complex [40-43]. The phosphorylated tyrosines can then serve as docking sites for the Syk family kinase ZAP70 which is recruited, phosphorylated and activated [44, 45]. ZAP-70 then phosphorylates the transmembrane adaptor protein LAT which can form complexes with many different signaling proteins (Grb2, GADs, and PLC- $\gamma$ 1) [46]. LAT also links receptor activation to the induction of the Grb2/SOS/ras pathway [47-50]. The above events take place very rapidly following antigen encounter suggesting the existence of a very sensitive switch capable of transforming external stimuli into cellular responses [51].

\section{Lipid Rafts and the Initiation and Propagation of TCR Signaling}

A central role is played by tyrosine phosphorylation in the regulation of the signaling cascade triggered by TCR engagement. An important part of this regulation is the spatial organization of components of this cascade, including kinases and phosphatases. There is sufficient experimental evidence in $\mathrm{T}$ lymphocytes that such a compartmentalization exists. In particular, it has been demonstrated biochemically that proteins like CD4, Lck, LAT, Fyn, Ras and PAG/Cbp are associated with lipid rafts, whereas others like CD45 are excluded from these domains in resting T cells [11, 52-59]. Upon engagement of the TCR in mature $\mathrm{T}$ cells by antigen/MHC recognition or antibody aggregation, different subunits of the CD3 complex inducibly translocate into lipid rafts $[11,53,60]$. Following activation, other components of the TCR signaling machinery are recruited into lipid rafts, such as SLP-76, ZAP-70, Vav, PLC- $\gamma 1$ and Grb2, [11, 46, 53, 60-64]. Of the tyrosine-phosphorylated proteins constitutively found in lipid rafts, the adaptor protein LAT is the most prominent. Targeting of LAT to lipid rafts has been shown to be necessary for optimal $\mathrm{T}$ cell activation [61]. The mechanisms responsible for the targeting of signaling proteins into lipid rafts are largely unknown, but addition of myristate and palmitate residues or GPI-anchors seems to be essential $[8,61,65]$.

Janes and collaborators [57] have illustrated the importance of lipid rafts in TCR signaling in a series of confocal microscopy studies. They have shown that GM1 (a raft-ganglioside) and TCR antibody cross-linking causes the aggregation of raft-associated proteins. The aggregates induced by GM1 cross-linking co-localized with certain raft-associated components (Lck, Fyn and LAT) and were resistant to non-ionic detergents, just like rafts that were isolated biochemically. Furthermore, CD45 phosphatase was excluded from these aggregates in accordance with the biochemical data. Interestingly, tyrosine phosphorylation and calcium influx, similar to that observed after TCR stimulation, were observed upon GM1 aggregation $[57,66]$.

\section{Lipid Rafts and the Negative Regulation of TCR Signaling}

The regulation of lymphocyte activation is a tightly controlled balance between co-stimulatory and inhibitory signals. In this way, thresholds for lymphocyte activation can be established after membrane-associated receptor signaling is initiated. The best studied inhibitory receptor in T cells is CTLA-4 (cytotoxic T lymphocyte antigen-4). It is a member of the CD28 family of co-receptors and binds to B7 molecules with higher affinity than CD28 [67, 68]. CTLA-4 is minimally expressed in resting $\mathrm{T}$ cells, but following antigen recognition, its surface expression rapidly increases due to increased synthesis and redistribution of the intracellular pool to the surface [69]. Previously, it had been reported that as a result of TCR and CD28 ligation, the number of GM1 positive peripheral T cells increases. In contrast, Martin and colleagues have shown that CTLA-4 profoundly inhibits the expression of surface lipid rafts following stimulation [70]. These results suggest that regulation of surface lipid rafts may be a mechanism by which co-stimulatory and inhibitory molecules regulate $\mathrm{T}$ cell activation.

\section{Lipid Rafts and Costimulation in T Cells}

As is the case with all lymphocytes, activation of immune receptors is greatly influenced by a variety of co-receptors. For optimal activation to occur, T lymphocytes require 2 independent signals from antigen-presenting cells (APCs). The first signal is mediated by the unique TCR and is antigen-specific. The second signal, or co-stimulation, is independent of the antigen receptor but required for sustained lymphocyte activation and proliferation as well as differentiation to effector and memory cells [71]. In T cells, binding of the co-stimulatory molecule CD28 to B7.1 (CD80) and B7.2 (CD86) molecules drastically influences signaling. CD28 binding lowers the threshold for $\mathrm{T}$ cell activation by allowing naïve $\mathrm{T}$ cells to respond to lesser numbers of engaged TCRs [72]. Indeed, it was demonstrated that CD28 co-stimulation increases phosphorylation levels and permits sustained signaling in naïve $\mathrm{T}$ cells. Using antibody-coated beads, Viola and colleagues [73, 74] have shown that co-engagement of CD3 and CD28 at the contact between $\mathrm{T}$ cells and APCs induces the redistribution and coalescence of membrane lipid rafts. According to their model, CD28-induced fusion of lipid rafts at contact sites between T cells and APCs represents a mechanism to create an environment for sustained TCR signaling. Furthermore, the natural tendency of these domains to fuse upon stimulatory cell-cell contacts can be observed following antibody or lectinmediated binding to lipid raft components. However, recent reports suggest the that protein-protein interactions are more important than detergent insolubility in regulating the assembly of signaling complexes in the plasma membrane, and the exact temporal and functional relationship between lipid raft coalescence, TCR signaling and immune synapse formation remains to be established $[75,76]$. 


\section{Membrane-Associated Cholesterol and TCR Signaling}

Several studies have shown that lipid raft disruption by cholesterol sequestering agents (filipin, methyl- $\beta$-cyclodextrin) attenuates TCR signaling following antigen-receptor engagement. Extraction of cholesterol by methyl- $\beta$-cyclodextrin has been shown to redistribute lipid raft components and reduce both calcium and tyrosine phosphorylation events [11, 53]. Xavier and colleagues [53] used the cholesterol sequestering antibiotics filipin or nystatin to demonstrate that optimal TCR-mediated signal transduction cannot be obtained unless lipid raft integrity is maintained, thus suggesting an essential role for lipid rafts in initiating intracellular signals. As stated previously, lipid rafts may indeed facilitate signaling by being a site of receptor recruitment, acting as a platform where activated signaling molecules may interact and then initiate downstream effector cascades. It is also possible that lipid rafts could also function to segregate signaling molecules in resting cells. Although lipid raft disruption results in decreased TCRinduced signaling, 1 recent report has described a transient increase in the basal tyrosine phosphorylation and activation of the Ras-ERK pathway following methyl-b-cyclodextrin treatment. The rapid (15 min after treatment) removal of LAT and Lck from lipid rafts was accompanied by an increase in tyrosine phosphorylation and activation of the ras pathway [77]. These experiments highlight the importance of cholesterol in regulating signaling pathways in $\mathrm{T}$ lymphocytes. Lipid raft disruption can also be achieved by adding excessive amounts of ganglioside GM1 to the cells [78]. Jurkat cells treated with high amounts of exogenous GM1 show an inhibition in their anti-CD3-induced tyrosine phosphorylation and calcium influx [53].

\section{Lipid Rafts and the Development and Differentiation of $T$ Cells}

The somatic diversification of immune receptors spawns an extensive array of specificities to foreign antigens, but also inherently includes auto-immune specificities. There exist several mechanisms of immune tolerance to prevent these auto-reactive lymphoid cells from differentiating and maturing into harmful effectors. Newly emerging $\mathrm{T}$ and B lymphocytes that express functioning immune receptors differentiate into naïve cells that are then assayed for auto-reactivity in central organs, such as the thymus and the bone marrow. Immature cells bearing receptors that can engage with a self-antigen are eliminated by apoptosis. Cells surviving this selection procedure differentiate into mature lymphocytes and acquire the ability to productively respond to receptor ligation. Thus, the consequences of antigen binding to lymphocyte receptors differ during lymphocyte development, as they range from cell death at the immature stage to cell proliferation and effector function in the periphery.

The molecular mechanisms linking receptor stimulation to these distinct biological responses are not known, but several recent observations indicate a possible role for lipid rafts in reg- ulating cellular responses during development. There is ample evidence that the presence of multichain immune recognition receptors (MIRRs) in lipid rafts is developmentally regulated, and the accessibility of immune receptors to lipid rafts could represent a key step determining the outcome of receptor engagement. In contrast to classical antigen-receptors expressed by mature lymphocytes, both the pre-BCR and pre-TCR expressed by immature lymphocytes (pre-B cells and CD4- CD8thymocytes) localize in lipid rafts before antigen encounter [79]. Although the structural features or putative ligands able to interact with these 'pre-receptors' remain elusive, their association in these signaling platforms may represent an important mechanism conferring a constitutive signaling capacity leading to cell survival. In marked contrast, immune receptors (BCR and TCR) expressed by immature B and T lymphocytes (CD4+ CD8+ thymocytes) are excluded from lipid rafts, and recent studies indicate that upon antigen encounter, these receptors are not recruited in lipid rafts [17, 80-82]. Furthermore, defects in positive selection of CD4+ CD8+ thymocytes (mutation in the TCR a-chain connecting peptide domain and CD3d-deficient mice) were associated with reduced phosphorylation of several intracellular substrates, such as Lck, ZAP-70, CD3 $\zeta$ and LAT, in lipid rafts $[83,84]$. It is, therefore, tempting to speculate that the physical segregation of receptors from lipid rafts and downstream signaling effectors at the immature stage represent an important mechanism in central tolerance. Thus, receptor signaling 'outside' lipid rafts may lead to cell death, whereas signaling 'within' lipid rafts (as described in mature cells) would induce a productive cellular response. The mechanisms underlying these regulated lipid raft associations are presently unknown but may involve developmental changes in the affinity of immune receptors for lipid rafts or alterations in the membrane composition restricting or enhancing the mobility of receptors into lipid rafts.

Lipid rafts have also been implicated at later stages of development. Depending on the cytokines they produce and their respective function, CD4+ T lymphocytes are divided in different categories [85-87]. Th1 cells produce high levels of IL-2 and IFN- $\gamma$ and play an important role in inflammatory and cellular responses, whereas Th2 cells produce high levels of IL-4 and IL-5 and are involved in humoral and allergic immune responses. Prior to differentiation, T lymphocytes produce IL-2, proliferate and possess the ability to secrete both IL-4 and IFN- $\gamma$ before developing into Th1 or Th 2 cells. The final phenotypic fate of differentiating $\mathrm{T}$ cells is influenced by a number of factors, including the type and concentration of antigen, the type of APC, the cytokine environment and the nature and strength of co-stimulatory signals [88-91]. Differences in the regulation and activation of intracellular signals have been described for both Th1 and Th2 cells. The changes in early signaling events observed between the Th1 and Th2 subtypes are reflected at the transcriptional level [92, 93], such that the regulation of different MAP kinase pathways has been described $[94,95]$, and Th2 cells have also been shown to 
have defects in sustaining calcium mobilization upon TCR ligation [96, 97]. Balamuth et al. [98] biochemically analyzed the basis for these signaling differences in lipid rafts from resting and stimulated polarized murine Th1 and Th2 cells. They observed no difference in the protein composition of lipid rafts between both subsets in the resting state, and both subsets showed significant CD4 recruitment upon activation. However, Th2 cells were unable to recruit the TCR and the CD45 phosphatase into lipid rafts upon activation like Th1 cells. The lipid raft-associated ganglioside GM1 was co-localized with the TCR in Th1 but not in Th2 cells at the site of T cell/APC contact. Also, Th1 cells displayed calcium mobilization that was dependent on lipid raft integrity, while Th2 cells were able to mobilize calcium even when lipid rafts were disrupted by treatment with cyclodextrins [98]. These experiments suggest Th1 and Th2 cells display different membrane organization and may explain how identical signals can be interpreted differently in both subtypes.

\section{FceRI Signaling}

Lymphocytes are not the only cells of the immune system in which lipid rafts play an important role during activation and signaling. FceRI, the high-affinity receptor for $\operatorname{IgE}$ is expressed on basophils and mast cells. The receptor aggregates upon the binding of oligomeric antigens to receptor-bound $\mathrm{IgE}$. The Fc receptor is a tetramer composed of $1 \alpha-, 1 \beta$ - and $2 \gamma$-chains. The $\gamma$-chain binds the Fc portion of $\operatorname{IgE}$ and the $\beta$ and $\gamma$-chains contain the ITAMs necessary for signal transduction $[99,100]$. The activation Lyn leads to the phosphorylation of the ITAMs and the recruitment of Syk, which is then phosphorylated, leading to the activation of PLC- $\gamma 1$. Activation of PLC- $\gamma 1$ leads to histamine degranulation and calcium release $[12,99,101]$. Studies examining receptor detergent solubility first suggested a role for lipid rafts in FceRI signaling. Field and colleagues demonstrated that the FceRI receptor is detergent-soluble in quiescent cells, but a large fraction becomes detergent-insoluble and lipid raft-associated when aggregated with antibody [102, 103]. This association of lipid rafts with cross-linked FceRI receptors occurs before tyrosine phosphorylation of the receptor, and therefore, only lipid raft-associated receptors are tyrosine-phosphorylated [103]. Furthermore, FceRI cross-linking induces the redistribution of lipid raft components, including gangliosides and GPI-linked proteins, to aggregates observed by confocal microscopy [104].

\section{Lipid Rafts and Pathogens}

A great number of pathogens utilize lipid rafts to enter and exit cells. Several different groups have shown that pathogens can hijack the inherent property of lipid rafts to sequester and concentrate potential ligands. This is not surprising given the importance of lipid rafts in immune cell signaling discussed above. By hijacking immune responses, pathogens are able to create a hospitable environment for entry, replication and latency. The importance of lipid rafts in host-pathogen interactions has been explored in last few years [105-107]. It has been shown that a number of different viruses use lipid rafts to exert their pathogenic effects by gaining control of host cells. In addition to providing a point of entry, lipid rafts may allow viruses to bypass degradation in lysosomes thus promoting intracellular survival.

Van der Goot and Harder [106] have shown that bacterial toxins use lipid rafts to enter cells. As discussed above, lipid rafts concentrate a number of receptors, and it has been shown that many toxin-associated membrane receptors reside in rafts, thus promoting toxin oligomerization [106, 108]. As described earlier, the ganglioside GM1 is a lipid raft-associated molecule, and on target cells it is recognized by the cholera toxin- $\mathrm{B}$ subunit. Cholera toxin is comprised of $1 \mathrm{~A}$ subunit and $5 \mathrm{~B}$ subunits. The catalytic A subunit controls adenylate cyclase activity by ADP-ribosylation of $\mathrm{G}$ proteins $[109,110]$. The B subunit binds GM1 with low affinity, but when all 5 subunits bind, the global affinity increases. Orlandi and Fishmann [111] have shown that cholesterol depletion by filipin does not affect cholera toxin binding but does inhibit its internalization and cAMP accumulation. These data suggest that GM1-rich domains provide a preferential entry site cholera toxin binding, and binding is enhanced in plasma membrane regions where GM1 is concentrated, namely the lipid rafts. Shin and collaborators [112] have shown that the bacteria Escherichia coli become intracellular pathogens by targeting lipid rafts as entry points to host cells. E. coli bacteria enter mast cells through lipids rafts following the interaction of the FimH adhesion protein with the GPI-linked receptor CD48. Entering a cell via a lipid raft containing vacuole may enable the bacteria to avoid destruction lysosomes [105].

The Epstein-Barr virus (EBV) establishes a latent infection in resting $\mathrm{B}$ cells, during which the viral gene product LMP2A (latent infection membrane protein) is expressed on the $\mathrm{B}$ cell surface [113]. LMP2A is a multi-membrane spanning protein containing a long cytoplasmic domain containing ITAMs that, upon phosphorylation, bind the Lyn and Syk tyrosine kinases, thus preventing them from participating in BCR signaling. It was thought that LMP2A competitively blocked BCR association with tyrosine kinases and therefore, inhibited BCR signaling. But, in fact, LMP2A can by itself propagate signals and was shown to substitute for the BCR in promoting the survival and development of pre-B cells in a transgenic model [114]. Dykstra and colleagues [115] have shown the constitutive presence of LMP2A in lipid rafts of EBV-immortalized human B cell lines. Its presence in lipid rafts is independent of its association with Lyn and prevents the trafficking and the activation-induced BCR translocation. By blocking BCR signaling, LMP2A may ensure viral persistence and block antigen trafficking and presentation.

Early studies in a variety of viruses showed that their viral envelope membranes had a different lipid composition than the 
host membranes from which they were derived. One example of this occurs in HIV-1, where the lipid layer surrounding newly produced virions is enriched in sphingolipids and cholesterol [116-119]. Furthermore, lipid raft proteins, such as the GPI-anchored Thy-1 and CD59 as well as the GM1 ganglioside, have been shown to be incorporated in HIV-1 particles while non-raft components, such as CD45, were excluded [116]. In addition, the HIV-1 proteins Nef, Gag and Env can be readily detected in lipid raft fractions [120-122]. Nef is one of the most abundant proteins expressed during the early phases of HIV gene expression and during viral latency. Experimental data suggest that Nef could promote $T$ cell activation [123]. It was shown that the association of Nef with lipid rafts via its NH2-myristoylation site was crucial for the initiation and propagation of $\mathrm{T}$ cell signaling, thereby promoting cytokine production and viral transcription [122]. Zheng and colleagues have shown that Nef increases virion infectivity in a cholesterol-dependent manner as a consequence of viral budding to lipid rafts [119]. Furthermore, different groups have reported that cholesterol depletion inhibits virus particle production and infectivity $[117,118,124]$. These observations led to the hypothesis that rafts may be involved in the assembly and budding of HIV-1. Manes and colleagues [117] were able to show that membrane cholesterol plays a crucial role in the fusion of the HIV-1 envelope and the plasma membrane, and furthermore, that lipid rafts enable the gp120-induced lateral association of the co-receptors CD4 and CXCR4. Kozak and colleagues [125] showed that these co-receptors segregated into distinct microdomains and suggested that the initial entry of HIV-1 might be initiated in lipid rafts containing CD4 prior to being dispersed and associated with $\mathrm{CXCR} 4$, thus, inducing the membrane fusion reaction. Therefore, lipid rafts seem to be very important in supporting HIV-1 propagation and infectivity.

Furthermore, it has been shown that lipid rafts are also important during viral assembly and budding of the Ebola and Marburg viruses [126]. A number of viral structural proteins, including those of influenza, Sendai, measles and rota viruses, have also been associated with lipid rafts, and the use of cholesterol-depleting agents to disrupt lipid rafts interferes with viral entry and suggests that lipid raft integrity is a prerequisite for their infectivity [127-130].

\section{Lipid Rafts and Statins}

Statins are competitive inhibitors of the 3-hydroxy-3-methylglutaryl co-enzyme A (HMG-CoA) reductase that are clinically used to reduce blood cholesterol levels. Statins, reduce cholesterol levels by inhibiting the conversion of HMG-CoA into mevalonate, the rate-limiting step in cholesterol synthesis.
Statins are used by a large number of the population to control high levels of blood cholesterol (hypercholesterolemia), a condition that has been linked to a number of coronary heart diseases including arteriosclerosis. In addition to their well documented effects on cholesterol blood levels, experimental evidence has shown that statins affect a wide variety of physiological processes. Using different drugs of the statin family (compactin and lovastatin), a couple of groups have shown that statins can modulate human lymphocyte functions in vitro [131, 132]. Goldman and colleagues [133] treated the human Jurkat $\mathrm{T}$ cell line with lovastatin and demonstrated an inhibition of both proximal and distal TCR-mediated signals. Another study has shown that lovastatin inhibits the early signaling events (such as calcium influx) induced by GPI-anchored proteins, such as CD59 and CD48 [134]. Pharmacological inhibition of HMG-CoA reductase has also been described to block natural killer cell cytotoxicity and signal transduction in LPS-induced murine pre-B lymphocytes $[135,136]$ and to reduce MHC class II expression in APCs [137]. Several groups have demonstrated inhibition of activation and proliferation in lymphocytes treated with statins in vitro [138, 139]. Lawman and colleagues demonstrated in vivo that atorvastatin delays Lupus development and inhibits auto-reactive B cell activation in a lupus-prone strain of mice [140]. It is tempting to speculate that statins have the ability to affect the signaling properties of immune cells by disrupting the integrity of lipid rafts, but due to the mechanism by which statins work it is possible that other cellular processes are affected. Recent evidence suggests that statins can selectively impair the function of Ras, a member of the GTPase superfamily, thus inhibiting $\mathrm{T}$ cell activation [141]. Therefore, while it is possible that statins affect immune cell signaling, more evidence is needed about the global consequences inhibition of HMG-CoA reductase has on cells.

\section{Conclusions}

Growing experimental evidence has placed lipid rafts in the spotlight, as they provide specialized microenvironments in which a large number of biological processes take place. They concentrate relevant molecules involved in distinct intracellular processes and may represent a specific and organized manner to initiate, propagate and sustain signaling. They also serve as the signaling platforms for a great number of immune receptors on $\mathrm{T}$ and B lymphocytes as well as on mast cells. Upon receptor ligation, lipid rafts can pre-assemble signaling proteins in a restricted membrane area and allow rapid signaling to downstream cascades. They can also permit sustained signaling by stabilizing signaling complexes and impeding the lateral movement of certain membrane proteins. 


\section{References}

1 Singer SJ, Nicolson GL: The fluid mosaic model of the structure of cell membranes. Science 1972;175 (23):720-731.

2 Edidin M: Lipids on the frontier: a century of cellmembrane bilayers. Nat Rev Mol Cell Biol 2003; 4(5):414-418

3 Ohvo-Rekila H, et al: Cholesterol interactions with phospholipids in membranes. Prog Lipid Res 2002;41(1):66-97.

4 Cherukuri A, et al: Isolation of lipid rafts from B lymphocytes. Methods Mol Biol 2004;271:213-224.

$\checkmark 5$ Cheng PC, et al: Floating the raft hypothesis: the roles of lipid rafts in B cell antigen receptor function. Semin Immunol 2001;13(2):107-114.

6 Simons K, Toomre D: Lipid rafts and signal transduction. Nat Rev Mol Cell Biol 2000;1(1):31-39.

7 Brown DA, London E: Functions of lipid rafts in biological membranes. Annu Rev Cell Dev Biol 1998;14:111-136.

8 Brown DA, London E: Structure and function of sphingolipid- and cholesterol-rich membrane rafts. J Biol Chem 2000;275(23):17221-17224.

$\checkmark$ Horejsi V, et al: Signal transduction in leucocytes via GPI-anchored proteins: an experimental artefact or an aspect of immunoreceptor function? Immunol Lett 1998;63(2):63-73.

10 Cherukuri A, Dykstra M, Pierce SK: Floating the raft hypothesis: lipid rafts play a role in immune cell activation. Immunity 2001;14(6):657-660.

11 Montixi C, et al: Engagement of T cell receptor triggers its recruitment to low-density detergentinsoluble membrane domains. Embo J 1998;17 (18):5334-5348.

12 Sheets ED, Holowka D, Baird B: Membrane organization in immunoglobulin $\mathrm{E}$ receptor signaling. Curr Opin Chem Biol 1999;3(1):95-99.

$\checkmark 13$ Parpal S, et al: Cholesterol depletion disrupts caveolae and insulin receptor signaling for metabolic control via insulin receptor substrate-1, but not for mitogen-activated protein kinase control. J Biol Chem 2001;276(13):9670-9678.

14 Reth M, Wienands J: Initiation and processing of signals from the B cell antigen receptor. Annu Rev Immunol 1997:15:453-479.

15 Kurosaki T: Functional dissection of BCR signaling pathways. Curr Opin Immunol 2000;12(3): 276-281.

16 Campbell KS: Signal transduction from the B cell antigen-receptor. Curr Opin Immunol 1999;11(3): 256-264

17 Chung JB: Baumeister MA, Monroe JG: Cutting edge: differential sequestration of plasma membrane-associated $\mathrm{B}$ cell antigen receptor in mature and immature B cells into glycosphingolipid-enriched domains. J Immunol 2001;166(2):736-740.

18 Cheng PC, et al: A role for lipid rafts in B cell antigen receptor signaling and antigen targeting. J Exp Med 1999;190(11):1549-1560.

19 Aman MJ, Ravichandran KS: A requirement for lipid rafts in B cell receptor induced $\mathrm{Ca}(2+)$ flux Curr Biol 2000;10(7):393-396.

20 Petrie RJ, et al: Transient translocation of the B cell receptor and Src homology 2 domain-containing inositol phosphatase to lipid rafts: evidence toward a role in calcium regulation. J Immunol 2000;165(3):1220-1207.

21 Sproul TW, Cheng PC, Dykstra ML, Pierce SK: A role for MHC class II antigen processing in B cell development. Int Rev Immunol 2000;19(2-3): 139-155.

22 Ravetch JV, Bolland S: IgG Fc receptors. Annu Rev Immunol 2001;19:275-290.
Ravetch JV, Lanier LL: Immune inhibitory receptors. Science 2000;290(5489):84-89.

24 Ono M, et al: Role of the inositol phosphatase SHIP in negative regulation of the immune system by the receptor Fc(gamma)RIIB. Nature 1996;383 (6597):263-266.

25 Aman MJ, Tosello-Trampont AC, Ravichandran $\mathrm{K}$ : Fc gamma RIIB1/SHIP-mediated inhibitory signaling in B cells involves lipid rafts. J Biol Chem 2001;276(49):46371-46378

26 Banchereau J, et al: The CD40 antigen and its ligand. Annu Rev Immunol 1994;12:881-922.

27 Vidalain PO, Azocar O, Servet-Delprat C, Rabourdin-Combe C, Gerlier D, Manie S: CD40 signaling in human dendritic cells is initiated within membrane rafts. Embo J 2000;19(13):33043313.

28 Hostager BS, Catlett IM, Bishop GA: Recruitment of CD40 and tumor necrosis factor receptorassociated factors 2 and 3 to membrane microdomains during CD40 signaling. J Biol Chem 2000;275(20):15392-15398.

29 Malapati S, Pierce SK: The influence of CD40 on the association of the $\mathrm{B}$ cell antigen receptor with lipid rafts in mature and immature cells. Eur J Im munol 2001;31(12):3789-3797.

30 Fearon DT, Carroll MC: Regulation of B lymphocyte responses to foreign and self-antigens by the CD19/CD21 complex. Annu Rev Immunol 2000; 18:393-422.

31 Cherukuri A, Cheng PC, Pierce SK: The role of the CD19/CD21 complex in B cell processing and presentation of complement-tagged antigens. J Immunol 2001;167(1):163-172.

32 Cherukuri A, et al: The CD19/CD21 complex functions to prolong B cell antigen receptor signaling from lipid rafts. Immunity 2001;14(2):169-179.

33 Sandel PC, Monroe JG: Negative selection of immature B cells by receptor editing or deletion is determined by site of antigen encounter. Immunity 1999;10(3):289-299.

34 Gauld SB, Dal Porto JM, Cambier JC: B cell anti gen receptor signaling: roles in cell development and disease. Science 2002;296(5573):1641-1642.

35 Su TT, et al: PKC-beta controls I kappa B kinase lipid raft recruitment and activation in response to BCR signaling. Nat Immunol 2002;3(8):780-786.

36 Chung JB, et al: Incomplete activation of CD4 T cells by antigen-presenting transitional immature B cells: implications for peripheral B and T cell responsiveness. J Immunol 2003;171(4):1758-1767.

37 Norvell A, Mandik L, Monroe JG: Engagement of the antigen-receptor on immature murine B lymphocytes results in death by apoptosis. J Immunol 1995;154(9):4404-4413

38 Karnell FG, et al: Membrane cholesterol content accounts for developmental differences in surface B cell receptor compartmentalization and signaling. J Biol Chem 2005;280(27):25621-25628.

39 Ellmeier W, Sawada S, Littman DR: The regulation of CD4 and CD8 coreceptor gene expression during $\mathrm{T}$ cell development. Annu Rev Immunol 1999:17:523-554.

40 Weiss A, Littman DR: Signal transduction by lymphocyte antigen receptors. Cell 1994;76(2): 263-274.

41 Chan AC, Shaw AS: Regulation of antigen receptor signal transduction by protein tyrosine kinases. Curr Opin Immunol 1996;8(3):394-401.

42 Wange RL, Samelson LE: Complex complexes: signaling at the TCR. Immunity 1996;5(3):197205.
3 Van Leeuwen JE, Samelson LE: T cell antigen-receptor signal transduction. Curr Opin Immunol 1999;11(3):242-248

44 Chan AC, et al: The zeta chain is associated with a tyrosine kinase and upon T-cell antigen receptor stimulation associates with ZAP-70, a 70-kDa tyrosine phosphoprotein. Proc Natl Acad Sci US A 1991;88(20):9166-9170.

45 Chan AC, et al: ZAP-70: a $70 \mathrm{kd}$ protein-tyrosine kinase that associates with the TCR zeta chain. Cell 1992;71(4):649-662.

46 Zhang W, et al: LAT: the ZAP-70 tyrosine kinase substrate that links $\mathrm{T}$ cell receptor to cellular activation. Cell 1998;92(1):83-92.

47 Finco TS, et al: LAT is required for TCR-mediated activation of PLCgamma1 and the Ras pathway. Immunity 1998;9(5):617-626.

48 Zhang W, et al: Association of Grb2, Gads, and phospholipase C-gamma 1 with phosphorylated LAT tyrosine residues. Effect of LAT tyrosine mutations on $\mathrm{T}$ cell antigen receptor-mediated signaling. J Biol Chem 2000;275(30):23355-23361.

49 Samelson LE: Signal transduction mediated by the $\mathrm{T}$ cell antigen receptor: the role of adapter proteins. Annu Rev Immunol 2002;20:371-394.

50 Lin J, Weiss A: Identification of the minimal tyrosine residues required for linker for activation of T cell function. J Biol Chem 2001;276(31):2958829595.

51 Ferrell JE Jr: How regulated protein translocation can produce switch-like responses. Trends Biochem Sci 1998;23(12):461-465.

52 Langlet $\mathrm{C}$, et al: Membrane rafts and signaling by the multichain immune recognition receptors. Curr Opin Immunol 2000;12(3):250-255.

53 Xavier R, et al: Membrane compartmentation is required for efficient $\mathrm{T}$ cell activation. Immunity 1998;8(6):723-732.

54 Rodgers W, Rose JK: Exclusion of CD45 inhibits activity of p56lck associated with glycolipid-enriched membrane domains. J Cell Biol 1996;135(6 Pt 1):1515-1523.

55 Xavier R, Seed B: Membrane compartmentation and the response to antigen. Curr Opin Immunol 1999;11(3):265-269.

56 Millan J, et al: CD4 segregates into specific detergent-resistant T-cell membrane microdomains. Tissue Antigens 1999;53(1):33-40.

-57 Janes PW, Ley SC, Magee AI: Aggregation of lipid rafts accompanies signaling via the $\mathrm{T}$ cell antigen receptor. J Cell Biol 1999;147(2):447-461.

58 Kawabuchi M, et al: Transmembrane phosphoprotein Cbp regulates the activities of Src-family tyrosine kinases. Nature 2000;404(6781):999-1003.

59 Brdicka T, et al: Phosphoprotein associated with glycosphingolipid-enriched microdomains (PAG), a novel ubiquitously expressed transmembrane adaptor protein, binds the protein tyrosine kinase csk and is involved in regulation of $\mathrm{T}$ cell activation. J Exp Med 2000;191(9):1591-604.

60 Kosugi A, et al: Translocation of tyrosine-phosphorylated TCRzeta chain to glycolipid-enriched membrane domains upon T cell activation. Int Immunol 1999;11(9):1395-1401.

61 Zhang W, Trible RP, Samelson LE: LAT palmitoylation: its essential role in membrane microdomain targeting and tyrosine phosphorylation during T cell activation. Immunity 1998:9(2):239-246.

62 Boerth NJ, et al: Recruitment of SLP-76 to the membrane and glycolipid-enriched membrane microdomains replaces the requirement for linker for activation of $\mathrm{T}$ cells in $\mathrm{T}$ cell receptor signaling. J Exp Med 2000;192(7):1047-1058. 
63 Bi K, Altman A: Membrane lipid microdomains and the role of PKCtheta in T cell activation. Semin Immunol 2001;13(2):139-146.

64 Bi K, et al: Antigen-induced translocation of PKCtheta to membrane rafts is required for $\mathrm{T}$ cell activation. Nat Immunol 2001;2(6):556-563

65 Kabouridis PS, Magee AI, Ley SC: S-acylation of LCK protein tyrosine kinase is essential for its signalling function in T lymphocytes. Embo J 1997;16 (16):4983-4998.

66 Janes PW, et al: The role of lipid rafts in T cell antigen receptor (TCR) signalling. Semin Immunol 2000;12(1):23-34

67 Chambers CA, Allison JP: CTLA-4 - the costimulatory molecule that doesn't: regulation of T-cell responses by inhibition. Cold Spring Harb Symp Quant Biol 1999;64:303-312.

68 Chambers CA, Kuhns MS, Allison JP: Cytotoxic $\mathrm{T}$ lymphocyte antigen-4 (CTLA-4) regulates primary and secondary peptide-specific CD4(+) T cell responses. Proc Natl Acad Sci U S A 1999;96 (15):8603-8608.

69 Chambers CA, et al: CTLA-4-mediated inhibition in regulation of $\mathrm{T}$ cell responses: mechanisms and manipulation in tumor immunotherapy. Annu Rev Immunol 2001;19:565-594.

70 Martin M, et al: Cytotoxic T lymphocyte antigen 4 and CD28 modulate cell surface raft expression in their regulation of $\mathrm{T}$ cell function. J Exp Med 2001;194(11):1675-1681

71 Frauwirth KA, Thompson CB: Activation and inhibition of lymphocytes by costimulation. J Clin Invest 2002;109(3):295-299.

72 Viola A, Lanzavecchia A: T cell activation determined by $\mathrm{T}$ cell receptor number and tunable thresholds. Science 1996;273(5271):104-106.

73 Viola A, et al: T lymphocyte costimulation mediated by reorganization of membrane microdomains. Science 1999;283(5402):680-682.

74 Viola A: The amplification of TCR signaling by dynamic membrane microdomains. Trends Immunol 2001;22(6):322-327.

75 Lee KH, et al: T cell receptor signaling precedes immunological synapse formation. Science 2002; 295(5559):1539-1542.

76 Lin J, Shaw AS: Getting downstream without a Raft. Cell 2005;121(6):815-816.

77 Kabouridis PS, et al: Cholesterol depletion disrupts lipid rafts and modulates the activity of multiple signaling pathways in T lymphocytes. Eur J Immunol 2000;30(3):954-963.

78 Simons M, et al: Exogenous administration of gangliosides displaces GPI-anchored proteins from lipid microdomains in living cells. Mol Biol Cell 1999;10(10):3187-3196.

79 Guo B, et al: Engagement of the human pre-B cell receptor generates a lipid raft-dependent calcium signaling complex. Immunity 2000;13(2):243-253.

80 Ebert PJ, Baker JF, Punt JA: Immature CD4+ $\mathrm{CD} 8+$ thymocytes do not polarize lipid rafts in response to TCR-mediated signals. J Immunol 2000; 165(10):5435-5442.

81 Saint-Ruf C, et al: Different initiation of pre-TCR and gammadeltaTCR signalling. Nature 2000;406 (6795):524-527.

82 Sproul TW, et al: Cutting edge: B cell antigen receptor signaling occurs outside lipid rafts in immature B cells. J Immunol 2000;165(11):6020-6023.

83 Delgado P, et al: CD3delta couples T-cell receptor signalling to ERK activation and thymocyte positive selection. Nature 2000;406(6794):426-430.
84 Werlen G, Hausmann B, Palmer E: A motif in the alphabeta T-cell receptor controls positive selection by modulating ERK activity. Nature 2000;406 (6794):422-426.

85 Abbas AK, Murphy KM, Sher A: Functional diversity of helper T lymphocytes. Nature 1996;383 (6603):787-793.

86 Mosmann TR, Sad S: The expanding universe of T-cell subsets: Th1, Th2 and more. Immunol Today 1996;17(3):138-146.

87 Reiner SL, Seder RA: T helper cell differentiation in immune response. Curr Opin Immunol 1995;7 (3):360-366.

88 Moser M, Murphy KM: Dendritic cell regulation of TH1-TH2 development. Nat Immunol 2000;1 (3):199-205

89 Leitenberg D, Bottomly K: Regulation of naive $\mathrm{T}$ cell differentiation by varying the potency of TCR signal transduction. Semin Immunol 1999;11 (4):283-292

90 Constant S, et al: B lymphocytes can be competent antigen-presenting cells for priming CD4+ T cells to protein antigens in vivo. J Immunol 1995;155 (8):3734-3741.

91 Constant SL, Bottomly K, Induction of Th1 and Th2 CD4+ T cell responses: the alternative approaches. Annu Rev Immunol 1997;15:297-322.

92 Murphy KM, et al: Signaling and transcription in T helper development. Annu Rev Immunol 2000; 18:451-494.

93 Asnagli H, Murphy KM: Stability and commitment in T helper cell development. Curr Opin Immunol 2001;13(2):242-247.

94 Rincon M, et al: Interferon-gamma expression by Th1 effector $\mathrm{T}$ cells mediated by the p38 MAP kinase signaling pathway. Embo J 1998;17(10): 2817-2829.

95 Dumont FJ, et al: Inhibition of T cell activation by pharmacologic disruption of the MEK1/ERK MAP kinase or calcineurin signaling pathways results in differential modulation of cytokine production. J Immunol 1998;160(6):2579-2589.

96 Gajewski TF, Fitch FW: Anti-proliferative effect of IFN-gamma in immune regulation. IV. Murine CTL clones produce IL-3 and GM-CSF, the activity of which is masked by the inhibitory action of secreted IFN-gamma. J Immunol 1990;144(2): 548-556.

97 Gajewski TF, Schell SR, Fitch FW: Evidence implicating utilization of different $\mathrm{T}$ cell receptor-associated signaling pathways by $\mathrm{TH} 1$ and $\mathrm{TH} 2$ clones. J Immunol 1990;144(11):4110-4120.

98 Balamuth F, Leitenberg D, Unternaehrer J, Mellman I, Bottomly K: Distinct patterns of membrane microdomain partitioning in Th1 and th 2 cells. Immunity 2001;15(5):729-738.

99 Kinet JP: The high-affinity IgE receptor (Fc epsilon RI): from physiology to pathology. Annu Rev Immunol 1999;17:931-972.

100 Nadler MJ, et al: Signal transduction by the highaffinity immunoglobulin E receptor Fc epsilon RI: coupling form to function. Adv Immunol 2000;76: 325-355.

101 Sheets ED, Holowka D, Baird B: Critical role for cholesterol in Lyn-mediated tyrosine phosphorylation of FcepsilonRI and their association with detergent-resistant membranes. J Cell Biol 1999; 145(4):877-887.

102 Field KA, Holowka D, Baird B: Structural aspects of the association of FcepsilonRI with detergentresistant membranes. J Biol Chem 1999;274(3): $1753-1758$.
103 Field KA, Holowka D, Baird B: Compartmentalized activation of the high affinity immunoglobulin E receptor within membrane domains. J Biol Chem 1997;272(7):4276-4280.

104 Holowka D, Sheets ED, Baird B: Interactions between $\mathrm{Fc}$ (epsilon)RI and lipid raft components are regulated by the actin cytoskeleton. J Cell Sci 2000;113(Pt 6):1009-1019.

105 Rosenberger CM, Brumell JH, Finlay BB: Microbial pathogenesis: lipid rafts as pathogen portals Curr Biol 2000;10(22): 823-825.

106 Van der Goot FG, Harder T: Raft membrane domains: from a liquid-ordered membrane phase to a site of pathogen attack. Semin Immunol 2001;13 (2):89-97.

107 Manes S, del Real G, Martinez AC: Pathogens: raft hijackers. Nat Rev Immunol 2003;3(7):557568

108 Fivaz M, Abrami L, van der Goot FG: Landing on lipid rafts. Trends Cell Biol 1999;9(6):212-213.

109 Montecucco C, Papini E, Schiavo G: Bacterial protein toxins penetrate cells via a four-step mechanism. FEBS Lett 1994;346(1):92-98.

110 Montecucco C, Schiavo G: Mechanism of action of tetanus and botulinum neurotoxins. Mol Microbiol 1994;13(1):1-8.

111 Orlandi PA, Fishman PH: Filipin-dependent inhibition of cholera toxin: evidence for toxin internalization and activation through caveolae-like domains. J Cell Biol 1998;141(4):905-915.

112 Shin JS, Gao Z, Abraham SN: Involvement of cellular caveolae in bacterial entry into mast cells. Science 2000;289(5480):785-788.

113 Longnecker R, Miller CL: Regulation of EpsteinBarr virus latency by latent membrane protein 2 . Trends Microbiol 1996;4(1):38-42.

114 Caldwell RG, et al: Epstein-Barr virus LMP2A drives $\mathrm{B}$ cell development and survival in the absence of normal B cell receptor signals. Immunity 1998;9(3):405-411.

115 Dykstra ML, Longnecker R, Pierce SK: EpsteinBarr virus coopts lipid rafts to block the signaling and antigen transport functions of the BCR. Immunity 2001;14(1):57-67.

116 Nguyen DH, Hildreth JE: Evidence for budding of human immunodeficiency virus type 1 selectively from glycolipid-enriched membrane lipid rafts. J Virol 2000;74(7):3264-3272.

117 Manes S, et al: Membrane raft microdomains mediate lateral assemblies required for HIV-1 infection. EMBO Rep 2000;1(2):190-196.

118 Ono A, Freed EO: Plasma membrane rafts play a critical role in HIV-1 assembly and release. Proc Natl Acad Sci U S A 2001;98(24):13925-13930.

119 Zheng YH, et al: Nef increases infectivity of HIV via lipid rafts. Curr Biol 2001;11(11):875-879.

120 Lindwasser OW, Resh MD: Multimerization of human immunodeficiency virus type $1 \mathrm{Gag}$ promotes its localization to barges, raft-like membrane microdomains. J Virol 2001;75(17):79137924.

121 Rousso I, et al: Palmitoylation of the HIV-1 envelope glycoprotein is critical for viral infectivity. Proc Natl Acad Sci USA 2000;97(25):1352313525

122 Wang JK, et al: The Nef protein of HIV-1 associates with rafts and primes $\mathrm{T}$ cells for activation. Proc Natl Acad Sci US A 2000;97(1):394-399.

123 Hanna Z, et al: Nef harbors a major determinant of pathogenicity for an AIDS-like disease induced by HIV-1 in transgenic mice. Cell 1998;95(2):163175

124 Dimitrov DS: Cell biology of virus entry. Cell 2000;101(7):697-702. 
125 Kozak SL, Heard JM, Kabat D: Segregation of CD4 and CXCR4 into distinct lipid microdomains in T lymphocytes suggests a mechanism for membrane destabilization by human immunodeficiency virus. J Virol 2002;76(4):1802-1815.

126 Bavari S, et al: Lipid raft microdomains: a gateway for compartmentalized trafficking of Ebola and Marburg viruses. J Exp Med 2002;195(5):593-602.

127 Parton RG, Lindsay M: Exploitation of major histocompatibility complex class I molecules and caveolae by simian virus 40. Immunol Rev 1999; 168:23-31.

128 Manie SN, et al: Measles virus structural components are enriched into lipid raft microdomains: a potential cellular location for virus assembly. J Virol 2000;74(1):305-311.

129 Vincent S: Gerlier D, Manie SN: Measles virus assembly within membrane rafts. J Virol 2000;74 (21):9911-9915.

130 Ali A, et al: Influenza virus assembly: effect of influenza virus glycoproteins on the membrane association of M1 protein. J Virol 2000;74(18):87098719 .
131 Cuthbert JA, Lipsky PE: Sterol metabolism and lymphocyte responsiveness: inhibition of endogenous sterol synthesis prevents mitogen-induced human T cell proliferation. J Immunol 1981;126 (6):2093-2099.

132 Cutts JL, Bankhurst AD: Suppression of lymphoid cell function in vitro by inhibition of 3-hydroxy-3methylglutaryl coenzyme A reductase by lovastatin. Int J Immunopharmacol 1989;11(8):863-869.

133 Goldman F, et al: Lovastatin inhibits T-cell antigen receptor signaling independent of its effects on ras. Blood 1996;88(12):4611-4619.

134 Stulnig TM, et al: Signal transduction via glycosyl phosphatidylinositol-anchored proteins in T cells is inhibited by lowering cellular cholesterol. J Biol Chem 1997;272(31):19242-19247.

135 Muldoon MF, et al: Effects of lovastatin on the immune system. Am J Cardiol 1997;80(10):13911394.

136 Muldoon MF, et al: Immune system differences in men with hypo- or hypercholesterolemia. Clin Immunol Immunopathol 1997;84(2):145-149.
137 Kwak B, et al: The HMG-CoA reductase inhibitor simvastatin inhibits IFN-gamma induced MHC class II expression in human vascular endothelial cells. Swiss Med Wkly 2001;131(3-4):41-46.

138 Reedquist KA, Pope TK, Roess DA: Lovastatin inhibits proliferation and differentiation and causes apoptosis in lipopolysaccharide-stimulated murine B cells. Biochem Biophys Res Commun 1995;211(2):665-670.

139 Rudich SM, et al: HMG-CoA reductase inhibitors pravastatin and simvastatin inhibit human B-lymphocyte activation. Transplant Proc 1998;30(4): 992-995.

140 Lawman S, et al: Atorvastatin inhibits auto-reactive B cell activation and delays lupus development in New Zealand black/white F1 mice. J Immunol 2004;173(12):7641-7646.

141 Ghittoni R, et al: Simvastatin inhibits T-cell activation by selectively impairing the function of Ras superfamily GTPases. Faseb J 2005;19(6):605-607. 